\title{
Value management of enterprise equipment
}

\author{
Xiao Ming $\mathrm{Hu}^{1}$ \\ ${ }^{1}$ Dept. electronic \& electrical engineering , Wuhan railway vocational college of technology, \\ Wuhan, Chain. \\ Wuhan jiangxia district hidden dragon road,no.1 code 430205. \\ Email:huxiaolili@tom.com,
}

Keywords: OEE, TPM, value running time

\begin{abstract}
In the production and quality management of enterprises, the management of equipment should also be attached great importance, at present, there are many advanced theories in the world.. This paper focuses on the total productive maintenance (TPM), in the TPM can quantify the overall equipment effectiveness (OEE), enterprise in advocating OEE, in essence, is to eliminate eight waste, improve equipment starting value, the value of time management.
\end{abstract}

\section{TPM（Total Productive Maintenance)}

\subsection{TPM development history ${ }^{[2]}$}

In addition to the people of the enterprise equipment, the most advanced equipment operation management is TPM. TPM means "Total productive maintenance", which is a full participation in the production and maintenance, the main point in the "production and maintenance" and "full participation". TPM is a system of maintaining and improving the integrity of production and quality systems through the machines, equipment, processes, and employees that add business value to an organization.TPM is based on the establishment of the United States of production and maintenance system, but also absorbed the ideas of the British equipment integrated engineering, China's constitution in the constitution of the masses to participate in management.

In other countries, due to different national conditions, the understanding of TPM is: the activities of production and maintenance, including the operator, improve the overall performance of the equipment. Other said, Productive Equipment Management. TPM is a comprehensive production equipment management. This is a new kind of thought, which is developed by the international TPM Association. It makes in a factory installed TPM activities are more likely to be successful, it's flexible larger. That is to say you can according to the actual demand of the factory equipment to carry out TPM content, can also be said to be a dynamic method.

Maintenance of production is started from 1951, before 1951 called afterwards maintenance (BM) era, and then experience the preventive maintenance (PM), improvement and maintenance (CM), preventive maintenance (MP), then the total productive maintenance (TPM) to the 1980s also known as predictive maintenance (PDM) era. After the 80's in 21'Century, the emergence of the concept of predictive maintenance. for predict the failure of equipment, replacement of equipment failure may occur, so that the operation of equipment zero fault, to prevent accidents, and thus improve the efficiency (PDM).

\subsection{TPM concept}

TPM was originally defined in the narrow sense: all personnel, including corporate leadership, production workers and office staff to participate in the production of maintenance and maintenance systems. The purpose of TPM is to achieve the highest efficiency of the device, which is based on the group activity, involving the whole system of equipment.

With the expansion of TPM activity, the content of TPM has changed. In 1989, TPM was redefined as a generalized TPM. It is to establish sound, the pursuit of production efficiency of the system limit of enterprise system as the goal, embarks from the production system as a whole, to build the mechanism to avoid all the loss (disaster, poor, faults, etc.), relates to the production, research development, design, sales and management departments in all departments, through the 
company from the upper to the first-line employees full participation and repeated small group activities, and ultimately the purpose of zero loss.

The implementation of TPM has eight key points, also known as the TPM of the eight pillars:

1. individual improvement of equipment efficiency

The first pillar of the TPM is individual to improve equipment efficiency, namely according to the different status of equipment, such as equipment use, performance starting rate and qualified rate, life cycle, individual use of equipment, equipment enterprises overall utilization rate reached the highest. This system needs the cooperation of the whole department.

2. Establishment of autonomous maintenance system

The establishment of autonomous maintenance system refers to the use of equipment, "who is responsible for maintenance". the autonomous maintenance as a management of the enterprise, that is, to promote the staff to cultivate the spirit of ownership. Generally speaking, the autonomous maintenance system is mainly determined by the production department.

3. Establishment of maintenance system

Maintenance and inspection of equipment should have plan. As making a checklist, promote production department staff to operate timing to machine refueling, screw, wipe the dust; the equipment department regular inspection, check the machine if there is a problem, then use the production batch, the equipment for minor repairs and overhaul. These are all plans to protect the system, planning and maintenance system by the equipment department to complete the leadership.

4. Prevention and the establishment of primary flow management system

When purchasing a device, consider the method of maintenance of the equipment, so as to purchase the best equipment suitable for the production process. If the purchase of equipment, not only a waste of expenses, but also increased the difficulty of maintenance. Therefore, this system focuses on prevention, that is, before the purchase or design of the equipment to take full consideration of future maintenance issues. Charge for the research and development department mainly.

5. to establish the quality maintenance system ISO 9000

Quality maintenance system is also known as ISO 9000. Product quality is the life of the enterprise, there is no qualified quality assurance, it is difficult to make the customer feel assured. Although a lot of enterprises have reached the ISO 9000 certification, but truly meet the requirements of ISO 9000 is not much. Therefore, the establishment of this system requires the entire staff of the whole body of the investment, the quality of the product strategy to complete the production of the product.

6. education training

In the whole process, 5S or 6S must to promote education and training. In education and training, employees mentality education and retraining to be found the problems, solve problems, improve the efficiency of the ability, at the same time, in the enterprise make proposals for improvement activities, give full play to their creativity. Education and training by the personnel department.

7. The efficiency of the management of the indirect Department

Similar to the 5S activity, the production department, equipment department, the development department needs to implement TPM, other departments should cooperate with the implementation of TPM. Therefore, it is very important to realize the efficiency of production.

8. Safety, health and environmental management ISO 14000

Some 5S and TPM implementation of a good business, although not necessarily carried out ISO 14000 management, but generally will be the spirit of ISO 14000 is very good.

Eventually, the implementation of TPM to reach the efficiency of equipment life cycle cost evaluation and the overall efficiency of the equipment, whole system (refers to all methods of production and maintenance of the system involve is PM and MP, cm, BM and other are included), full participation in (refers to the equipment plan, use, maintenance, etc. all the departments to attend, is a particular focus on the operator independent group activities). To implement TPM, we must understand the efficiency of the equipment. 


\section{Overall Equipment Effectiveness}

OEE is the overall equipment effectiveness (overall equipment efficiency and overall equipment efficiency) of abbreviation, with the increasingly fierce market competition, manufacturing enterprises to want to continue to obtain the desired benefits, which is an important link is to continue to improve their production efficiency, in a "big manufacturing country" said China today, efficiency has become many enterprises whether can profit the key or even decisive factor. However, the majority of China's current production enterprises, especially private enterprises, the surface seemingly good operation of the production workshop does not actually to the best state of work, the value of equipment and operating personnel exists much room for improvement, which virtually for the enterprise caused huge losses. But the vast majority of enterprises management personnel did not aware of this, or just a sense of feeling, but there is a lack of quantitative data, and did not take effective measures to be addressed. In order to solve this problem, the concept of OEE is put forward in the international manufacturing industry. OEE is a simple and practical production management tools, in the manufacturing sector in the US and Europe and China's multinational corporations have been widely used, overall equipment efficiency index has become an important standard to measure the production efficiency of enterprises, but also of TPM implementation of one important way.

2.1 Calculations for OEE

OEE breaks the performance of a manufacturing unit into three separate but measurable components: Availability, Performance, and Quality. Each component points to an aspect of the process that can be targeted for improvement. OEE may be applied to any individual Work Center, or rolled up to Department or Plant levels. This tool also allows for drilling down for very specific analysis, such as a particular Part Number, Shift, or any of several other parameters. It is unlikely that any manufacturing process can run at 100\% OEE. Many manufacturers benchmark their industry to set a challenging target; $85 \%$ is not uncommon.

OEE is calculated with the formula

OEE $=($ Availability $) *($ Performance $) *($ Quality $)$

\section{Availability}

The Availability portion of the OEE Metric represents the percentage of scheduled time that the operation is available to operate. The Availability Metric is a pure measurement of Uptime that is designed to exclude the effects of Quality, Performance, and Scheduled Downtime Events. The losses due to wasted availability are called availability losses. ${ }^{[6]}$

Example: A given Work Center is scheduled to run for an 8-hour (480 minute) shift with a 30minute scheduled break.

Operating Time $=450$ Min Sched -60 Min Unsched Downtime $=390$ Minutes

Calculation: Availability = operating time / scheduled time

Availability 390 minutes / 450 minutes $=86.6 \%$

\section{Performance and productivity}

Also known as "process rate", the Performance portion of the OEE Metric (also known as process rate) represents the speed at which the Work Center runs as a percentage of its designed speed. The Performance Metric is a pure measurement of speed that is designed to exclude the effects of Quality and Availability. The losses due to wasted performance are also often called speed losses. In practice it is often difficult to determine speed losses, and a common approach is to merely assign the remaining unknown losses as speed losses.

\section{Calculation: Performance}

(Productivity) $=$

(Parts Produced * Ideal Cycle Time) / Operating time ${ }^{[7]}$

Example:

A given Work Center is scheduled to run for an 8-hour (480 minute) shift with a 30-minute scheduled break.

Operating Time $=450$ Min Sched -60 Min Unsched Downtime $=390$ Minutes

The Standard Rate for the part being produced is 40 Units/Hour or 1.5 Minutes/Unit 
The Work Center produces 242 Total Units during the shift. Note: The basis is Total Units, not Good Units. The Performance metric does not penalize for Quality.

Time to Produce Parts $=242$ Units $* 1.5$ Minutes $/$ Unit $=363$ Minutes

Performance (Productivity) $=363$ Minutes $/ 390$ Minutes $=93.0 \%$

\section{Quality}

The Quality portion of the OEE Metric represents the Good Units produced as a percentage of the Total Units Started. The Quality Metric is a pure measurement of Process Yield that is designed to exclude the effects of Availability and Performance. The losses due to defects and rework are called quality losses.

Calculation: Quality $=$ (Units produced - defective units) $/$ (Units produced)

\subsection{The example of OEE}

If the total working time is $8 \mathrm{~h}$, the scheduled downtime is $20 \mathrm{~min}$, and the fault stop is $20 \mathrm{~min}$, the installation of the fixture is $20 \mathrm{~min}$, and the time is $20 \mathrm{~min}$. There are 400 parts processing, the theoretical machining cycle is $0.5 \mathrm{~min}$, the actual processing cycle is $0.8 \mathrm{~min}$. If still using the above example, if the equipment qualified rate is $98 \%$,

We get:

(A) working hours per day $=60 \times 8=480 \mathrm{~min}$.

(B) planned downtime (production, maintenance plan, morning session, etc.) $=20 \mathrm{~min}$.

(C) load time per day $=\mathrm{A}-\mathrm{B}=460 \mathrm{~min}$.

(D) downtime loss per day $=60 \mathrm{~min}$.

(E) start time every day. $=\mathrm{C}-\mathrm{D}=400 \mathrm{~min}$.

(F) the number of production per day $=400$ pieces.

(G) qualified product rate $=98 \%$.

$(\mathrm{H})$ theoretical processing cycle $=0.5 \mathrm{~min} /$ piece.

(I) actual processing cycle $=0.8 \mathrm{~min} /$ piece.

(J) actual processing time $=\mathrm{I} \times \mathrm{F}=0.8 \times 400=320 \mathrm{~min}$.

$(\mathrm{K})$ Availability $=(\mathrm{E} / \mathrm{C}) \times 100 \%=(400 / 460) \times 100 \%=87 \%$.

Performance (Productivity) $=$

(Parts Produced $*$ Ideal Cycle Time) / Operating time $=\mathrm{L} \times \mathrm{M} \times 100 \%=0.625 \times 0.80 \times 100 \%$ $=50 \%$.

Finally, OEE $=\mathrm{K} \times \mathrm{N} \times \mathrm{G} \times 100 \%=0.87 \times 0.50 \times 0.98 \times 100 \%=42.6 \%$

\subsection{The essence of OEE formula}

\section{OEE $=$ Performance $\times$ Availability $\times$ Quality}

$=($ activation time $/$ load time $) \times($ the number of processed $\times$ actual processing cycle $/$ harvest time $) \times($ theoretical machining cycle $/$ actual processing cycle $) \times($ qualified production $/$ processing number)

$=($ activation time $\times$ number of processed $\times$ actual processing cycle $\times$ theory processing cycle $\times$ eligible production) / (load time $\times$ crops dynamic time $\times$ the actual processing cycle $\times$ number of processed)

$\mathrm{OEE}=$ (theoretical machining cycle $\times$ qualified output $) /$ load time $=$ qualified product of the total time / load time theory

The essence of OEE is that it is worth starting time. That is, the value of the starting time of the total available production time (load time) ratio.

From the point of view of time, calculate OEE is qualified net production time (start time) accounted for the total production time available (load time) ratio, the essence is the value of the starting time .That is, not only to inspect the equipment on time use, also to investigation due to caused by the operation and process performance and reduce the qualified product rate, so enterprises of equipment value management is to enhance the value of the starting time.

In short, the goal of TPM can be summarized as four "zero", that is, the zero downtime, zero waste, zero accident, zero speed loses.

Enterprise implementation of OEE, can obviously improve the manpower and equipment 
production efficiency, reduce product defective rate, and can shorten the cycle of production and management, reduce the number of unnecessary loss, cost savings, to enable enterprises to gain more profit, achieve better comprehensive benefits, these are tangible effect of TPM activities, also comprehensively reflects the full participation thought pays attention to the equipment and management time value.

\section{References}

[1] The management and control of quality, james. R.evans; William .Mlindsay. Beijing, Renmin University of China press, 2010. ISBN-978-7-300-12027-0.P8,30.

[2] TPM, http://wenku.baidu.com/view/.

[3] ISO9001 : 2008 quality management system documents, Chai Bangxian et al., Beijing, Mechanical Industry Press, 2013. ISBN-978-7-111-27658-6.P29, 262.

[4] Research and application of comprehensive efficiency of OEE equipment, http://wenku.baidu.com.

[5].Overall equipment effectiveness.https://en.wikipedia.org.

[6] "Understanding Availability". Retrieved 9, Oct 2014. https://en.wikipedia.org.

[7]"OEE Primer: Calculating OEE". Retrieved 9, Jul 2013. https://en.wikipedia.org. 